Thélème. Revista Complutense de Estudios Franceses ISSN-e: 1989-8193

http://dx.doi.org/10.5209/THEL.59715

\title{
El viaje y su ilustración: la función de la imagen en los relatos franceses de viajes (siglos XVI-XIX)
}

\author{
Cristina G. de Uriarte Marrón ${ }^{1}$
}

Recibido: 24 de marzo de 2018 / Aceptado: 10 de julio de 2018

Resumen. El abundante material iconográfico que genera la literatura de viajes no solo constituye un complemento de la parte escrita, sino que cumple, también, una innegable función estética. A partir de ejemplos representativos de una quincena de relatos de viajes franceses, que comprenden un periodo que abarca los siglos XVI-XIX, nos proponemos reflexionar acerca de la función de la imagen y su evolución en dichas obras. En un primer momento nos centraremos en la representación, real y fabulada, de lugares y personas; seguidamente, abordaremos la ilustración científica y el paisaje para concluir con algunas precisiones sobre las imágenes en este género literario.

Palabras clave: relatos franceses de viajes, iconografía, siglos XVI-XIX.

\section{[fr] Le voyage et son illustration : la fonction de l'image dans les récits de voyages français $\left(\mathrm{XVI}^{\mathrm{e}}\right.$-XIX ${ }^{\mathrm{e}}$ siècles)}

Résumé. L'abondant matériel iconographique produit par la littérature de voyages n'est pas seulement un complément de la partie écrite, mais remplit aussi une indiscutable fonction esthétique. Dans cet article nous nous proposons d'étudier la fonction de l'image et son évolution dans une quinzaine de récits de voyages français qui comprennent une période qui s'étend du XVI ${ }^{\mathrm{e}}$ au XIX ${ }^{\mathrm{e}}$ siècle. Dans un premier temps nous nous centrerons sur la représentation, réelle et imaginée, des lieux et des personnes ; ensuite, nous aborderons l'illustration scientifique et du paysage avant de conclure avec quelques précisions sur les images dans ce genre littéraire.

Mots clés : récits de voyages français, iconographie, $\mathrm{XVI}^{\mathrm{e}}-\mathrm{XIX}{ }^{\mathrm{e}}$ siècles.

\section{[en] Travel and illustration: the function of image in French travel narratives (16th - 19th centuries)}

Abstract. The abundant iconographic material generated by travel narratives not only constitutes a complement of the written text, but it also fulfils an undeniable aesthetic function. Based on representative examples of fifteen French travel writing, comprised between the 16th and the 19th centuries, this article will study the function and the evolution of image in those texts. First, it will focus on the representation, real and fictional, of places and people; then, it will look at scientific illustration and landscape; finally, it will reflect on the relationship between images and the written text in this literary genre.

Keywords: French travel narratives, iconography, XVI-XIX century.

\footnotetext{
1 Universidad de la Laguna curiarte@ull.edu.es
} 
Sumario: 1. La representación de nuevas tierras y sus gentes. 2. La ilustración científica y el paisaje. 3. Algunas consideraciones finales sobre las imágenes en el relato. 4. Conclusión.

Cómo citar: G. de Uriarte, C. (2018). "El viaje y su ilustración: la función de la imagen en los relatos franceses de viajes (siglos XVI-XIX)". Thélème. Revista Complutense de Estudios Franceses, Vol.33, Núm. 2: 259-273.

Desde los testimonios más antiguos la imagen, en cualquiera de sus formas, se encuentra indisolublemente unida a la escritura. Esta relación es bastante imprecisa en sus inicios hasta que la representación iconográfica adopta de la literatura el principio denominado "narración progresiva". La unión definitiva entre texto e imagen tiene lugar cuando ambos aparecen simultáneamente en el rollo ilustrado de papiro, fruto de un largo proceso que comprende varios siglos de la antigüedad griega (Weitzmann, 1990: 19).

Uno de los ejemplos que mejor refleja la conexión existente entre el contenido lingüístico y el visual lo encontramos en los manuscritos iluminados ${ }^{2}$, cuyas miniaturas cumplen diferentes finalidades: embellecer, ilustrar o, sencillamente, informar; o, dicho de otro modo, pueden carecer de vinculación con el texto, ponerlo en imágenes o completarlo. Sin embargo, es en la cartografía donde esta relación es más estrecha $^{3}$. Con las informaciones contenidas en los relatos de viajes se elaboran mapas que, además de cumplir una innegable función pedagógica, constituyen una poderosa herramienta de propaganda política y religiosa. En ellos sus autores combinan las representaciones con todo tipo de comentarios y aclaraciones. Así, junto a la imagen de los océanos surcados por diferentes tipos de embarcaciones, lugares lejanos repletos de riquezas, animales y escenas étnicas encontramos explicaciones sobre las nuevas rutas marítimas y su explotación comercial o referencias a la historia y a las particularidades geográficas y etnográficas de los nuevos territorios y sus habitantes. Todo ello posee un indiscutible valor pues, si bien es cierto que en no pocas ocasiones la fantasía se apodera de los lugares y las personas, no lo es menos que aporta una información de primer orden acerca de la representación de las diversas culturas en el imaginario occidental del momento.

Fuera del ámbito circunscrito a la cartografía y desde un punto de vista mucho más amplio, las imágenes han constituido desde siempre un importante medio de comunicación y su función, como ya hemos señalado, va más allá de la meramente ornamental, llegando a alcanzar cierta autonomía con respecto al texto. En su estudio sobre el papel que desempeña la imagen para los historiadores, Burke (2008) propone diez reglas -que, en su mayoría, son aplicables al relato de viajes- para realizar su valoración crítica. La primera de ellas tiene que ver con la memoria y, más concretamente, con la interpictorialidad o intervisualidad, un concepto que procede del de intertextualidad y que alude a la influencia de imágenes preexistentes. Según este autor, cuando el observador está familiarizado con ellas y las reconoce se trata de citas visuales

2 Además de obras religiosas y literarias muy pronto se ilustran también textos científicos, pues su contenido requiere de dibujos aclaratorios para la correcta comprensión de lo escrito.

3 Así, en la Cosmographia -título con el que se traduce del griego al latín la obra, en ocho volúmenes, de Claudio Ptolomeo-, las ilustraciones están precedidas de breves descripciones. Otro ejemplo, de naturaleza diferente, nos lo proporciona el Libro del conosçimiento, anónimo castellano redactado hacia 1385. De inspiración cartográfica, esta recopilación ilustrada de maravillas fue considerada durante mucho tiempo un relato de viajes verídico y dio lugar, a su vez, a otras imágenes. 
aunque este conocimiento previo posibilita, además, la realización de parodias. Al mismo tiempo, al igual que sucede con la escritura, es posible hablar de tópicos visuales, lo que significa que no siempre lo representado es fruto de la observación directa. En el caso contrario, quizá confiando en el desconocimiento del observador de la iconografía original, el artista se sirve de trabajos creados para otros contextos y con otros fines. Sea como fuere, no hay duda alguna de que la presencia de la imagen condiciona inevitablemente la interpretación de la obra por parte del receptor.

En la literatura de viajes, calificada por Ette (2008: 35) de "género traductor", pues traslada una experiencia individual a una colectividad, comprobamos que recurrir a la visualización de lo observado es, además de una práctica ancestral, indispensable, en especial cuando se trata de explicar lo exótico, lo distinto, lo nuevo. La dificultad inherente a la descripción verbal de lo desconocido encuentra entonces en la representación visual, que habla directamente al lector, una herramienta de inestimable valor. El ilustrador adquiere, por tanto, un protagonismo evidente y se apropia, en cierto modo, del discurso interpretando y completando lo relatado y ofreciendo, a veces, su particular visión de los lugares, las personas y los hechos. En otro orden de cosas, conviene recordar que en el imprescindible proceso de selección de lo que merece ser dibujado intervienen criterios de diferente naturaleza -políticos, científicos o estéticos- que no son excluyentes entre sí. Así, por ejemplo, si el espíritu ilustrado y su vocación enciclopédica guían la labor de dibujantes y pintores en el siglo XVIII, en la centuria siguiente la atención se desvía hacia lo "pintoresco" y el paisaje se convierte en tema recurrente. Por otro lado, es importante señalar que no siempre coinciden en el tiempo texto e imagen. Aunque por lo general las ilustraciones forman parte del propósito inicial del viaje y son simultáneas al relato, al menos en su composición inicial, en ocasiones son resultado de decisiones posteriores y responden a criterios editoriales o políticos.

En las líneas que preceden, al igual que a lo largo de este artículo, nos referimos al relato de viajes entendido en su sentido habitual, esto es, la crónica, realizada en primera persona, de un desplazamiento realmente efectuado. Como señala Le Huenen en uno de sus estudios más conocidos (1990: 15), en esta forma de escritura tienen cabida textos de procedencia diversa: testimonios de geógrafos, historiadores y naturalistas, pero también de misioneros, comerciantes o militares. Estos materiales suelen contener, aunque de forma desigual, mapas, planos, dibujos, croquis y acuarelas que reproducen plantas, animales, vistas de ciudades o retratos de sus habitantes que no solo constituyen un complemento de la parte escrita conforme a una tradición que reconoce el valor didáctico de la imagen ${ }^{4}$, sino que cumplen, también, una innegable función estética. Ejecutado unas veces por grabadores profesionales, que trabajan por encargo y desconocen aquello que representan en sus planchas, y otras por viajeros que sí tienen ocasión de contemplar personalmente aquello que luego reproducen ${ }^{5}$, el abundante material iconográfico que genera el relato de viajes

$4 \quad$ Esta es una de las razones que explican la frecuente reutilización de las láminas para ilustrar los mismos contenidos en obras diferentes. Una práctica, por otra parte, usual ya antes de la invención de la imprenta y que Weitzmann (1990: 99) denomina "migración de miniaturas". Otro problema de distinta naturaleza surge cuando hay modificaciones posteriores y la relación entre texto e imagen se ve alterada por la traducción o la manipulación del texto original.

5 Lo cierto es que hasta el siglo XVIII el ilustrador no viaja y es a partir de este periodo cuando el artista es, al mismo tiempo, viajero al convertirse en un miembro más de la tripulación de las grandes campañas de navegación que marcan esta centuria y la primera mitad del siglo XIX. 
no ha llamado la atención de los estudiosos del mismo modo que lo ha hecho el soporte escrito. En este trabajo nos proponemos reflexionar acerca del papel que desempeñan estas imágenes en el relato. Su estudio nos permitirá comprobar que no solo son reflejo de una época -dotadas, en un primer momento, de una gran carga ideológica que evoluciona hacia el rigor y la precisión científica antes de convertirse en espejo del sentir individual del observador-, sino que también su evolución es paralela a la de esta forma de escritura ${ }^{6}$. Para ello hemos utilizado un corpus compuesto por una quincena de relatos de viajes franceses ${ }^{7}$ pertenecientes a un periodo que abarca desde el siglo XVI -fecha de la aparición en Francia del primer libro ilustrado sobre el continente americano, un lugar que despierta una considerable fascinación en el hombre europeo y que, como veremos más adelante, centra la atención de los ilustradores- hasta el siglo XIX, cuando la llegada de la fotografía altera de manera definitiva la relación entre palabra e imagen y la tradicional controversia sobre la fidelidad de lo dibujado carece ya de sentido. Siguiendo el orden habitual de aparición de las láminas en los relatos, en un primer momento nos centraremos en la representación, real y fabulada, de lugares y personas; seguidamente abordaremos la ilustración científica y el paisaje, para concluir con algunas precisiones sobre las imágenes en este género literario.

Antes de iniciar nuestro recorrido creemos necesario recordar brevemente que el desarrollo de diferentes técnicas de estampación -como la xilografía, el aguafuerte, la litografía o el grabado en bloques de madera - trae consigo una mayor calidad y precisión en las láminas, lo que facilita su aparición en toda clase de publicaciones, entre las que se incluyen, como no podía ser de otra forma, los libros de viajes. A esto hay que añadir la labor de grabadores y compiladores como Théodore de $\mathrm{Bry}^{8} \mathrm{o}$ el abate Prévost ${ }^{9}$ que dan a conocer a un público cada vez más numeroso noticias e informaciones que, aunque no siempre son verídicas, proponen un imaginario sobre

6 En esta ocasión únicamente nos interesaremos por las planchas que se insertan en el relato y no nos ocuparemos de los mapas o del análisis de otros elementos visuales como portadas o frontispicios, igualmente relevantes y cuya existencia suele responder a estrategias editoriales. Para más información sobre la relación entre viaje e imagen, vid., Requemora-Gros y Guyon (2012) donde las distintas contribuciones que conforman este volumen abordan diferentes aspectos sobre esta cuestión desde finales de la Edad Media hasta el siglo XIX. Igualmente, a través del enlace del proyecto Viaticalpes (https://www.unil.ch/viaticalpes/home/menuinst/presentation.html) de la Universidad de Lausana se puede acceder a una valiosísima base de datos sobre las imágenes contenidas en los relatos de viajes a Suiza y los Alpes entre los siglos XVI y XIX.

7 Los autores de estos textos son: Baudin, Cailliaud, Charnay, Dumont d'Urville, Feuillée, Freycinet, Frézier, Gaudichaud, Léry, Lesson, La Pérouse, d’Orbigny, Sonnerat y Thevet. Entre ellos hay marinos, naturalistas, dibujantes, geólogos o exploradores que forman parte de la tripulación de algunas de las circunnavegaciones más importantes de los siglos XVIII y XIX. Otros, como el franciscano Thevet o el ingeniero militar Frézier, viajan por motivos diferentes.

8 Este orfebre y grabador inicia en Alemania uno de los mayores proyectos editoriales de la historia a la que dan continuidad sus herederos: una gran colección de viajes que se extiende en el tiempo durante 44 años, concretamente desde 1590 a 1634. En ella se reproducen textos clásicos -en versión original, traducidos o reelaborados- de las principales expediciones europeas hacia América, Asia y África, acompañados de grabados ilustrativos -muchos de ellos coloreados-, bien insertados en el texto, bien como apéndices finales. Como consecuencia del éxito alcanzado entre el público europeo, algunas partes se reeditan. La serie dedicada al continente americano está ilustrada con 340 grabados y la relativa a Asia y África con 271.

9 A los 16 volúmenes que forman su Histoire générale des voyages editados entre 1746 y 1761 se suman tres de suplemento que ven la luz entre 1761 y 1770 . Aunque en un principio Prévost únicamente debe ocuparse de la traducción de una publicación periódica inglesa, muy pronto asume la recopilación y traducción de los relatos procedentes de todo el mundo desde el siglo XV. A pesar de las duras críticas recibidas, la trascendencia de este trabajo es incuestionable. 
lugares hasta entonces desconocidos que ejerce una notable influencia en el pensamiento colectivo de varias generaciones.

\section{La representación de nuevas tierras y sus gentes}

Durante mucho tiempo la reproducción fiel de la realidad no constituye un objetivo prioritario y la ilustración de lo diferente se construye a partir de la yuxtaposición de distintos elementos familiares siguiendo la práctica medieval "image-miroir" (Moureau, 2005: 37), que se aplica tanto a la descripción de las ciudades como a la de personas, animales o plantas. Ahora bien, los testimonios visuales no han sido siempre ni bien aceptados ni habituales. Si a mediados del siglo XVII el texto prevalece sobre la imagen -que se considera un lujo inútil, "objet de détournement de la lectura" (Briand, 2005: 219)-, a principios de la centuria siguiente los relatos de viajes contienen aún pocas ilustraciones, ya que los cronistas prefieren usar la palabra para describir y explicar lo nuevo. Morlin (2006: 19) propone como respuestas una razón práctica, al no contar siempre los viajeros con formación específica, y lo delicado de la reconstrucción a posteriori de lo visto, que explicaría la insistencia de algunos de ellos en que las planchas son una copia fiel del dibujo original. Esta situación cambia sustancialmente con el paso del tiempo. Así, las célebres instrucciones que recibe $\mathrm{La}$ Pérouse para su expedición iniciada en 1785 constituyen un modelo para numerosas empresas posteriores. En ellas se precisa, entre otras cuestiones, el cometido de los artistas embarcados cuya labor debe realizarse en estrecha colaboración con los científicos y consiste en: "les portraits des naturels des différents pays, leurs costumes, leurs cérémonies, leurs jeux, leurs édifices, leurs bâtiments de mer et toutes les productions de la terre et de la mer dans les trois règnes, dont le dessin pourra leur paraître utile pour faciliter l'intelligence des descriptions que les savants en auront faites" (Taillemite, 1999: 340). El número de dibujos elaborados alcanza tales proporciones que muchas veces se agrupan en volúmenes independientes.

Entre los objetivos prioritarios de estas ambiciosas campañas de navegación figura, aún en el siglo XVIII, la localización del continente austral que, de acuerdo con la idea heredada de la Grecia antigua acerca de la simetría entre los hemisferios norte y sur, debía estar situado a continuación de la Patagonia. Los mapas representan esta Terra australis incognita con la forma de un gran continente que equilibra, así, el globo terrestre.

Uno de los lugares que más curiosidad despierta entre el lector europeo es el continente americano, sinónimo de riquezas y emplazamiento de Eldorado. A lo largo del siglo XVI se forja una imagen particular del Nuevo Mundo basada en gran parte en las relaciones de viaje cuyos autores están acusados sistemáticamente de mentirosos. La razón reside en la tradición medieval que integra en los relatos y descripciones de lo nuevo mitos y leyendas antiguas e interpretaciones fabulosas de testimonios de segunda mano y cuyo mejor exponente es el Devisement du monde de Marco Polo. Las publicaciones que dan a conocer las tierras y costumbres de los nativos americanos ofrecen, por tanto, una visión estereotipada y llena de prejuicios en la que, a menudo, se exageran u omiten determinados aspectos en función de los gustos de la sociedad, de los intereses del grabador o editor que financia el trabajo o de la propaganda ideológica. Pero lo verdaderamente importante es que muchas de las ideas subyacentes en estas imágenes terminan calando en el pensamiento colectivo 
debido a la frecuencia con la que son empleadas en obras de todo tipo, contribuyendo, así, a forjar una percepción ficticia de América ${ }^{10}$ que sigue viva incluso en el siglo XVIII. Percepción que, por otro lado, afecta a cualquier territorio lejano, pues buena parte de la información aportada por los viajeros, pero también por comerciantes o embajadores, no procede de la observación directa (Magasich-Airola y de Beer, 1994: 190).

Junto a la fauna y a la flora exuberante del mundo tropical es recurrente la representación del "salvaje". Si en un primer momento se destacan su sencillez, inocencia y belleza ${ }^{11}$, pronto se convierte en el símbolo de la crueldad y los europeos en las víctimas de sus rituales sanguinarios. A esto se suma, en la segunda mitad del siglo XVI, la denuncia y condena de la conquista española y de las atrocidades cometidas en nombre de la fe. A este respecto, no olvidemos que, a pesar de la existencia de representaciones realistas que pueden ser consideradas "modelos etnográficos" (Duviols, 2006: 20), el lector habitual sigue fascinado por lo fantástico, lo maravilloso y lo sorprendente. En este contexto resulta imprescindible la referencia de nuevo a la extraordinaria influencia de los viajes editados por De Bry, en especial su serie dedicada a América y que Duviols sintetiza de la siguiente manera: "Son mérite est d'avoir fixé une image du Nouveau Monde qui deviendra une référence pendant des siècles. La contrepartie de cette réussite a été l'apparition des stéréotypes quasiment indéracinables" (2006: 217).

Dentro del continente americano Brasil es uno de los territorios que llama especialmente la atención: "Pendant environ trois cents ans, l'Amérique, sous ses atours barbares, représentée par une iconographie de caïmans, de princesse nue et emplumée, de cannibales, d'animaux merveilleux, est bien brésilienne" (Requemora-Gros, 2012: 400). Las razones de este imaginario son, según esta misma autora: el desconocimiento parcial de los viajes de Colón y el éxito de los de Américo Vespucio, el comercio del Palo de Brasil y el papel de la iconología.

El primer libro ilustrado publicado en Francia sobre estas tierras es obra del franciscano André Thevet, Les singularitez de la France antarctique (1558), autor, asimismo, de La Cosmographie Universelle (1575). En sus textos encontramos diferentes tipos de grabados. Mientras unos representan ejemplares de árboles y aves inverosímiles o escenas que reproducen aspectos tales como la antropofagia que practican los nativos o el tratamiento que reciben los prisioneros de las guerreras amazonas ${ }^{12}$; otros ilustran situaciones más próximas a la realidad, como pueden ser la elaboración de tabaco o la tala de madera y su transporte a las embarcaciones

10 Sobre la visión del continente, desde su descubrimiento hasta el siglo XVIII, a través de la literatura de viajes, vid., Duviols (1985).

11 Requemora-Gros (2012: 36-47) demuestra la influencia de las referencias históricas y literarias de la antigüedad en los relatos de viaje auténticos del siglo XVI que explica, por ejemplo, la idea de la superioridad de los indígenas americanos respecto al europeo civilizado. Esta visión ambivalente de una sociedad se refleja, igualmente, en los viajeros que, en este mismo periodo, se dirigen a África. En sus relatos se conjugan dos imágenes del continente: una positiva, que destaca su hospitalidad o su actividad comercial, y otra que resalta la poligamia o la esclavitud.

12 Thevet (1558: 124-127) dedica el capítulo 63 a las amazonas. Además de ofrecer detalles acerca del origen de su nombre o de su forma de vida recluida en pequeñas islas, el autor describe, y dibuja, cómo estas mujeres se defienden de los ataques continuos de sus enemigos a los que, una vez hechos prisioneros, cuelgan de una pierna a una rama de un árbol. Pasado un tiempo, si no han muerto les lanzan flechas y reducen a cenizas antes de comerlos. Dos siglos después, Charles-Marie de La Condamine -enviado a América por la Academia de Ciencias parisina para llevar a cabo observaciones científicas y donde permanece de 1735 a 1744 - aporta una nueva hipótesis más verosímil sobre la existencia de grupos de mujeres que, huyendo de la esclavitud, viven en comu- 
francesas y portuguesas. Otro paraje poseedor de un indudable atractivo es la Patagonia. Su particular localización en los confines del mundo lo convierte en la morada idónea de gigantes y animales fabulosos que son profusamente descritos y dibujados. E incluso se trazan mapas donde se sitúan estos seres imaginados, supliendo así una búsqueda infructuosa alimentada por lecturas y fantasías. El interés por este continente se mantiene a lo largo del tiempo como lo demuestra, por ejemplo, el encargo que el Gobierno francés realiza al explorador Désiré Charnay para llevar a cabo el estudio de las antiguas civilizaciones de México y América central y cuyos resultados son difundidos en diferentes publicaciones antes de ver la luz en forma de libro en $1885^{13}$.

En Brasil, el estrecho de Magallanes o la Patagonia se sitúan también hombres de elevadísima estatura. Diferentes mitos de distintas culturas atestiguan que los primeros hombres eran gigantes y Marco Polo asegura haberlos visto en las costas de Zanzíbar (2008: 317). A partir de las descripciones realizadas por Pigafetta en el relato de la circunnavegación de Magallanes, realizada entre 1519 y 1522, numerosos viajeros afirman haberlos encontrado y haber comprobado su fuerza desmesurada. Las referencias a estos gigantes de América se prolongan durante varios siglos aunque gradualmente los diferentes testimonios disminuyen sus proporciones hasta considerarlos sencillamente personas de gran estatura. Mientras Amédée Frézier realiza una digresión de dos páginas sobre la cuestión de los gigantes -“[...] un fait qu'on soupçonne d'abord de fausseté, quoique la lecture de l'Ecriture sainte \& des Historiens, \& les exemples des Geans, que nous voyons assez souvent naître \& vivre parmi nous, doivent nous disposer à croire quelque chose d'extraordinaire" (1716 : 80)-, Dumont d'Urville (1846) no solo los menciona, sino que también los representa. En el capítulo dedicado a las distintas naves que han cruzado el estrecho de Magallanes recuerda, entre otras cosas, la creencia según la cual los marinos desaparecidos en estas aguas han sido devorados por los gigantes patagones (1846: 70) o la expedición inglesa de Byron que en 1764 les atribuye, también a algunas de sus mujeres, una altura de incluso siete pies (1846: 70). Y en su Atlas pittoresque (1846) d'Urville incluye tres planchas (12-14): dos escenas grupales y una en la que figura el jefe vestido para la guerra junto a dos retratos, un hombre y una mujer. Unos años antes, sin embargo, Alcide d'Orbigny ya había afirmado en el segundo tomo de su Voyage: "[...] cependant mes Patagons et ceux de Magellan sont bien les mêmes, et les miens ne sont pas des géants. Il faut donc croire qu'il y a eu erreur manifeste" (1839-1843: 80).

La lista de seres prodigiosos descritos y dibujados es larga ${ }^{14}$. En ella se entremezclan utopías, herencias clásicas y nuevos descubrimientos, pues recordemos que el

nidad en zonas retiradas. Esta teoría es apoyada, algo más tarde, por Alexander von Humboldt (Magasich-Airola y de Beer, 1994: 156-159).

13 Tal como se indica en la obra, los 214 grabados y 19 mapas son resultado de la labor de una veintena de dibujantes. Como el propio Charnay señala al comienzo del relato (1885: 1), ya en 1857 había explorado una parte de México por encargo del Gobierno, aunque debido a su escasa preparación se limita a fotografiar los monumentos sin atreverse a acompañarlos de comentarios.

14 Enormes peces voladores al encuentro de los navegantes que surcan el Atlántico, gigantescos cocodrilos o la recurrente "vaca marina", entre otros monstruos, llenan los relatos hasta el siglo XVIII, cuando ríos y mares dejan de ser un sitio hostil. De todos ellos, uno de los animales que más páginas ocupa es el manatí. Desde la Edad Media se representa como un monstruo de forma híbrida y de grandes proporciones que para unos es la mujer pez africana, cuyos dientes poseen propiedades curativas, y para otros es una especie de vaca, un pez o un anfibio. Para más información, vid., Magasich-Airola y de Beer (1994: 188-215). 
lector ansía encontrar descripciones fabulosas; cuando la realidad no las proporciona el relator suple esta carencia con imaginación. Un ejemplo que ilustra la conjunción entre fantasía y realidad lo encontramos en Louis Feuillée que, entre 1707 y 1711 , lleva a cabo un viaje a América con el fin de efectuar observaciones astronómicas, geográficas y de historia natural. En su relato, junto a mapas, vistas de ciudades, perfiles de costas o radas, hay un dibujo del Monstruo de Buenos Aires sobre el que leemos:

Le contraste de trois ressemblances qu'il avoit avec un enfant, un cheval, \& un veau, surprit étrangement tous ceux qui le virent. [...] Je l'examinai d'assez près, $\&$ j'en dessinai, sans qu'on s'en apperçût, les traits principaux. D'abord que je fus retiré dans ma chambre, ayant dans mon imagination les especes toutes fraîches de ce monstre, elle me fournit ce qui manquoit au dessein que j'en avois commencé. Je le finis entierement, \& le représentai ensuite en sa couleur naturelle (1714: 242).

Feuillée describe con detalle este feto prematuro con cabeza humana y un cuerno en la frente que cuelga y esconde el ojo de toro, que se encuentra en medio del rostro, hasta alcanzar casi el labio superior. Y cuenta que decide acortar este cuerno en su dibujo para no esconder el ojo (1714: 243) $)^{15}$.

Por lo que concierne a las personas, se muestran bien en grupos, bien de forma individualizada. Llama la atención el hecho de que, con independencia de su origen, tienen un gran parecido entre sí y adoptan posturas similares. La forma más antigua de representación, y que se mantiene hasta el siglo XVII, son los tableaux (Moureau, 2005: 42), construidos en torno a un momento clave que sirve de referencia. Suele estar dividida en varios planos que cuentan historias -actividades cotidianas, ceremonias, intercambios entre nativos y europeos, batallas- o cumplen sencillamente una función descriptiva. Estas composiciones, en ocasiones algo alejadas de la realidad, están moldeadas por la influencia de diversos factores tales como la ideología dominante, el deseo de demostrar el éxito de la campaña o las dificultades derivadas de la representación de lo desconocido. A esto se añade el hecho de que ni el dibujante ni el grabador han visto lo representado. De ahí la tendencia a "occidentalizar" "un pittoresque qui ne lui parvient que par le truchement du récit viatique, lui-même tributaire d'un vocabulaire descriptif encore insuffisant avant la fin du XVIII siècle" (Moureau, 2005: 42).

Aunque hay retratos desde la época medieval y los grabados de Jean de Léry (1578) -acompañados de extensas y cuidadas descripciones de los indígenas-constituyen una excepción, a mediados del siglo XVIII las representaciones humanas siguen siendo minoritarias. Uno de los casos más llamativos es el de Bougainville, el primer francés en dar la vuelta al mundo (1766-1769). A pesar de que el aspecto humano está muy presente en el texto, la veintena de ilustraciones que lo acompañan se compone únicamente de mapas y dibujos técnicos. No obstante, el interés del hombre ilustrado por el encuentro y conocimiento del Otro -en el que todavía proyecta los ideales del paraíso original- explica que la iconografía de la segunda mitad de la centuria sea, además de cartográfica, esencialmente etnográfica.

15 Más adelante, en este mismo texto de Feuillée (1714: 485), encontramos reproducidos otros dos monstruos desproporcionados de aspecto humano. Uno de ellos, que muere tres días después de nacer, carece de brazos y luce un trozo de carne que cuelga por encima del rostro. El otro son dos niños unidos por el pecho. 
Si los primeros retratos son frontales, carecen prácticamente de decorado y el individuo es rápidamente identificable como distinto a través de su vestido o de los objetos que lleva, con el paso del tiempo prima el cuidado en la elección de los modelos y la precisión en la elaboración, aun cuando muchas de estas ilustraciones sigan trasladando una imagen amable de estas sociedades. En el lado opuesto figura, por ejemplo, la célebre Massacre de MM. De Langle, Lamanon et des dix autres individus des deux équipages incluida en el atlas de la campaña de La Pérouse publicado por Milet-Mureau (1797) y que da cuenta del trágico suceso ocurrido en las islas Samoa.

Además de las tradicionales escenas cotidianas, las láminas con hombres y mujeres ataviados con el vestido tradicional son muy numerosas. Con el fin de destacar lo exótico y lo pintoresco suelen aparecer de frente y de perfil o de espaldas, el centro de interés es el vestido y no la expresión del rostro ni ningún otro elemento secundario. Paralelamente, el tamaño de los personajes se reduce a la par que surge el decorado equilibrando, de este modo, la composición. Es entonces también cuando viajeros y dibujantes entran en escena, bien en forma de retratos en frontispicios y portadas, bien en el interior del relato captados en pleno desarrollo de su actividad reforzando, así, su función de testigo ocular de lo ilustrado, en un claro paralelismo con la misión desempeñada por el resto de los científicos. El frontispicio de Pierre Sonnerat (1776) constituye un buen ejemplo. Sentado a la sombra de unos cocoteros, se representa a sí mismo dibujando un pájaro que sostiene una indígena de Nueva Guinea, destino de la campaña. Y el dibujante Jacques Arago nos deja -además de ilustraciones de nativos, paisajes o escenas de caza- otros testimonios inusuales de la vida cotidiana del viaje alrededor del mundo (1817-1820) que realiza en la expedición al mando de Freycinet. Nos referimos a las escenas en las que aparece el capitán junto a su esposa, Rose, que embarca disfrazada de hombre. Se da la circunstancia de que su figura es eliminada del texto oficial, que sí aparece en otros relatos como el de la propia Rose.

El enorme atractivo que suscita América durante varios siglos puede equipararse al que despierta Oriente, cuya iconografía es especialmente relevante a partir del siglo XVIII. A medida que el conocimiento del mundo evoluciona el recurso a la fabulación disminuye, pues con el viaje se pretende antes confirmar datos y hechos que hallar maravillas. Al mismo tiempo, el estudio del hombre en su medio natural despierta un interés creciente que encuentra en la expedición a tierras australes de Nicolas Baudin (1800-1804) su mejor expresión, pues por primera vez las observaciones antropológicas ocupan un lugar privilegiado ${ }^{16}$.

\section{La ilustración científica y el paisaje}

En los siglos XVI y XVII el objetivo científico en las campañas no es aún prioritario y es esencialmente comercial y económico. Durante este periodo botánicos y zoólogos miran con recelo la actividad de los artistas, acusados de no representar con exactitud plantas y animales y de interesarse por los ejemplares más singulares sin

16 Como se pone de manifiesto desde la primera escala técnica que realizan en las islas Canarias. Para más información acerca de las imágenes de la población insular en los relatos de viajes del siglo XVIII, vid., G. de Uriarte (2006). 
prestar atención a los aspectos esenciales como el tamaño o el color, indispensables para identificar y reconocer especímenes. Esto explica la oposición de muchos científicos al uso de imágenes en sus trabajos, al considerarlas de poco valor para la historia natural. Sin embargo, con la realización de los grandes viajes de exploración en los siglos XVIII y primera mitad del XIX el progreso científico se convierte en un objetivo primordial. En este contexto, la formación especializada de la tripulación, compuesta por astrónomos, geógrafos, naturalistas y dibujantes profesionales, es determinante. Los mapas se levantan siguiendo los cálculos y mediciones de astrónomos y geógrafos, la ilustración de las plantas y los animales, pero también de ciudades y personas, corre a cargo de los dibujantes y naturalistas que, poco a poco, se van ganando la confianza de sus compañeros. Esto sucede con Nicolas Baudin, uno de los capitanes más escépticos con la labor de estos profesionales, que, sin embargo, afirma categórico: "Les dessins coloriés qui se trouvent dans mon journal, exécutés par les citoyens Martin Petit et Lesueur ne laissent à désirer pour la régularité et l'exactitude", “[...] un grand nombre d'animaux marins dont les dessins coloriés exécutés par les citoyens Petit et Lesueur ne laissent rien à désirer pour l'exactitude, le détail, la régularité et une parfaite ressemblance" (Bonnemains, 2000 : 137 y 173). Y Gaudichaud, autor de la relación de la circunnavegación de Freycinet (1817-1820), subraya el rigor con el que Poiret ha llevado a cabo las 120 planchas "pour interpréter et rendre avec exactitude les détails minutieux des parties des fleurs, ainsi que le port naturel de tous les végétaux figurés" (Gaudichaud, 1826: VI).

En el proceso que comprende desde la ejecución de los primeros croquis hasta la edición final, habitualmente el viajero se encarga solo del dibujo efectuado $d$ 'après nature, que es completado y adaptado ya en Europa. Un buen ejemplo de ello nos lo proporciona d'Orbigny. De su viaje a América (1826-1833) regresa -además de con importantes colecciones minerales, vegetales y animales, documentos, objetos y valiosas observaciones científicas- con un buen número de dibujos realizados por él mismo. Posteriormente, para la preparación y elaboración de los dos atlas que acompañan los siete volúmenes de texto se recurre a distintos profesionales que tienen cometidos diferentes:

Certains lithographient les paysages ou les scènes esquissés par d'Orbigny. D'autres gravent à l'eau-forte et au burin ses dessins d'histoire naturelle. Il faut aussi établir les dessins de centaines d'objets et de spécimens botaniques et zoologiques rapportés par le voyageur avant de les faire graver ou lithographier. [...] On engage aussi des coloristes chargés d'aquareller des planches en noir ou de rehausser les planches imprimées en couleurs (Schlup y Schmidt, 2001: 186).

La función de todas estas ilustraciones es servir de referencia para las disciplinas científicas. En este sentido, las imágenes son equiparables a las descripciones textuales y tan necesarias como la conservación de las muestras, incluso más cuando dicha conservación es imposible. Los dibujos realizados por Charles-Alexandre Lesueur ${ }^{17}$, más de 4500, que incluyen paisajes, retratos, animales o minerales, fruto de sus viajes por todo el mundo constituyen una buena muestra de la relevancia de la labor de

17 El Muséum d'histoire naturelle du Havre dispone de una colección de unos 8000 documentos (dibujos, manuscritos y documentos escritos) relacionados con Lesueur o su entorno cercano. 
los dibujantes. El reconocimiento definitivo a estos artistas queda patente cuando su nombre se hace visible y figura en las portadas al lado del autor.

Concluimos este apartado con una rápida mención al paisaje. Durante mucho tiempo su ilustración se limita principalmente a perfiles de costas en los que el mar suele estar en calma y las naves representan, simultáneamente, la patria y la expedición en curso. Símbolo del considerable riesgo para la propia vida, pero también del prestigio que supone formar parte de una empresa de estas características, en ocasiones las embarcaciones adquieren un protagonismo especial. Es el caso, por ejemplo, del relato de la campaña alrededor del mundo comandada por Duperrey (1822-1825) y redactada por Lesson. Después del frontispicio - un retrato de este zoólogo- la portada del primer tomo reproduce la corbeta La Coquille con la que se lleva a cabo la circunnavegación, una imagen que aparece de nuevo al final de la obra.

Tras el emplazamiento geográfico, desde finales del siglo XVIII las ilustraciones se hacen eco de la tradicional descripción ordenada en la que a la vista panorámica de ciudades y puertos le sucede el detalle de las calles, casas e iglesias para concluir con ejemplares de fauna y flora, retratos y escenas cotidianas de la población. De esta forma, la iconografía recrea el descubrimiento gradual de la nueva realidad que, siguiendo el principio de la filosofía de la naturaleza, se propone registrar, describir y clasificar el mundo visible (Despoix, 2005: 98). Paralelamente a la evolución del relato de viajes hacia la expresión de la subjetividad del relator, la representación de lo "pintoresco", de un paisaje marcado por una naturaleza frondosa y salvaje cobra relevancia: "[...] le paysage pur est une rareté avant la seconde moitié du XVIII" siècle, quand les 'sites pittoresques' comme les montagnes, les glaciers ou les cascades, etc., deviennent des sujets illustrables [...]” (Moureau, 2005: 36).

\section{Algunas consideraciones finales sobre las imágenes en el relato}

Partiendo de la premisa de que en el relato de viajes texto e imagen forman un único discurso y proponen una visión del mundo acorde con las expectativas de un lector que, recordemos, está ávido de información, es importante señalar que, del mismo modo que la palabra no describe todo, en el contenido visual se opera igualmente un proceso de selección en el que se priorizan los elementos más valiosos. De esta manera, y retomando la expresión de Briand (2005: 224), podemos hablar de "silencio iconográfico" respecto a aspectos tales como la vida a bordo, la travesía o el encuentro oficial entre europeos e indígenas, que históricamente han estado escasamente representados.

Por lo que concierne a la ubicación de las ilustraciones, no es fruto del azar y responde a criterios definidos de eficacia narrativa, tanto si suple lagunas textuales como si reitera lo narrado. Las imágenes se seleccionan y organizan, bien en forma de volúmenes independientes -que reciben el nombre de atlas historiques o pittoresques-, bien intercaladas en la narración ${ }^{18}$. Aunque no es lo habitual, en ocasiones

18 La publicación de los diferentes volúmenes no siempre sigue el orden tradicional según el cual la relación histórica de la campaña es la primera en ver la luz. Así, por ejemplo, el interés por dar a conocer cuanto antes los resultados del segundo viaje de Frédéric Cailliaud (1819-1822) a Egipto lleva a los editores a comenzar el proyecto con la parte iconográfica, mediante suscripción y por entregas, en 1823. 
están disociadas tipográficamente, es decir, carecen de alusiones textuales y es el lector quien presupone su sentido. La imagen y su leyenda aportan entonces información que el texto no proporciona y contextualizan la narración. Otras veces las planchas se encuentran separadas del fragmento que las menciona, incluso varias páginas, y es la leyenda la que establece el vínculo con el relato.

El último aspecto que queremos reseñar hace referencia al hecho de que durante mucho tiempo las imágenes no siempre han sido originales, esto es, no han sido elaboradas expresamente para la obra en cuestión, por lo que todavía en el siglo XVII es posible encontrar las mismas planchas en relatos diferentes. Un ejemplo nos lo proporciona Jean de Léry, que se inspira para su iconografía de los nativos brasileños en dos obras de Thevet -Les singularitez de la France Antartique (1558) y La Cosmographie Universelle (1575)- que, dicho sea de paso, comparten varios grabados ${ }^{19}$. Aun cuando algunos de ellos son inexactos, sirven de inspiración para otros trabajos como los del ya mencionado De Bry. Aunque los miembros de esta familia de grabadores nunca pisaron tierras americanas y se sirvieron de representaciones preexistentes que posteriormente adaptaron, sus ilustraciones de las principales expediciones a las Indias Orientales y Occidentales constituyeron durante mucho tiempo un modelo para autores posteriores.

\section{Conclusión}

Si bien es cierto que no todos los relatos de viajes incluyen imágenes y que hasta el siglo XVIII el número de láminas es relativamente escaso en proporción al lugar que ocupan las descripciones de lugares, hechos o personas, no lo es menos que la presencia de dibujos, grabados y acuarelas constituye una valiosa herramienta de propaganda política, religiosa o científica, además de un poderoso reclamo para el lector. Testimonio, en un primer momento, de una realidad efectivamente observada, pero también de otra imaginada, en el transcurso del tiempo la iconografía integra nuevos temas y objetivos a la vez que se desprende, de forma gradual, de la fabulación, que es sustituida por la reproducción fiel de los diferentes elementos de la naturaleza y el paisaje, en los que se proyectan, respectivamente, el conocimiento científico y las emociones.

El acercamiento a la imagen y al lugar que ocupa en el relato de viajes permite, por tanto, una mejor comprensión de determinados hechos y convicciones de una sociedad y de una época determinadas, toda vez que pone de manifiesto la transformación de la relación jerárquica tradicional según la cual el texto prevalece sobre la ilustración. De este modo, no solo vemos que la palabra llega, en ocasiones, a apoyarse en la imagen y la comenta, sino que con la publicación de los atlas se proporciona también una historia visual del viaje provista de identidad propia, al margen de la narración. Los cambios en las condiciones técnicas y materiales de reproducción de las ilustraciones o en la representación de determinadas creencias colectivas no son obstáculo alguno para la pervivencia de una de las funciones básicas de la imagen, la estética.

19 Esto sucede, concretamente, en la segunda edición del viaje de Jean de Léry (1580) en la que se añaden tres grabados de Thevet, ausentes en la primera edición. 


\section{Referencias bibliográficas}

Bonnemains, J. (ed.), (2000) Mon voyage aux Terres Australes. Journal personnel du commandant Baudin. París, Imprimerie Nationale.

Briand, C., (2005) "L'illustration du livre de voyage maritime au XVIII siècle" in Charon, A., T. Claerr \& F. Moureau (ed.), Le livre maritime au siècle des Lumières. Édition et diffusion des connaissances maritimes (1750-1830). París, Presses de l'Université ParisSorbonne, pp. 219-243.

Burke, P., (2008) "Cómo interrogar a los testimonios visuales" in Palos, J.L. \& D. CarrióInvernizzi (ed.), La historia imaginada. Construcciones visuales del pasado en la Edad Moderna. Madrid, Centro de Estudios Europa Hispánica, pp. 29-40.

Cailliaud, F., (1823-1827) Voyage à Méroé, au fleuve Blanc, au-delà de Fazoql dans le Midi du Royaume de Sennâr...[En línea]. París, Imprimerie Royale. Disponible en: http://gallica.bnf.fr/ark:/12148/bpt6k104932v.texteImage [Último acceso el 15 de enero de 2018].

Charnay, D., (1885) Les anciennes villes du Nouveau Monde. Voyages d'exploration au Mexique et dans l'Amérique Centrale [En línea]. París, Hachette. Disponible en: http:// gallica.bnf.fr/ark:/12148/bpt6k10733803.image [Último acceso el 15 de enero de 2018].

Despoix, P., (2005) Le monde mesuré. Dispositifs de l'exploration à l'âge des Lumières. Ginebra, Droz. Col. Bibliothèque des Lumières, vol. 67.

Dumont d'Urville, J.S.C., (1846) Voyage au Pôle sud et dans l'Océanie sur les corvettes L'Astrolabe et La Zélée exécuté par ordre du roi pendant les années 1837-1838-18391840. Atlas pittoresque, t. 1 [En línea]. París, Gide et $\mathrm{C}^{\mathrm{ie}}$. Disponible en: http://gallica.bnf. fr/ark:/12148/bpt6k97685c.image [Último acceso el 17 de enero de 2018].

Duviols, J.P., (1985) L'Amérique espagnole vue et rêvée. Les Livres de voyages de Christophe Colomb à Bougainville. París, Promodis.

Duviols, J.P., (2006) Le miroir du Nouveau Monde. Images primitives de l'Amérique. París, PUPS.

Ette, O., (2008) Literatura en movimiento: espacio y dinámica de una escritura transgresora. Madrid, CSIC.

Fayaud, V., (2014) "Dessins au long cours : albums français dans le Pacifique Sud au XVIII" et XIX ${ }^{\mathrm{e}}$ siècle" in E-rea [En línea]. No 11-2. Disponible en: https://erea.revues.org/3809 [Último acceso el 15 de diciembre de 2017].

Feuillée, L., (1714) Journal des observations physiques, mathématiques et botaniques [En línea]. París, Pierre Giffart. Disponible en: http://gallica.bnf.fr/ark:/12148/bpt6k96363749 [Último acceso el 17 de enero de 2018].

Freycinet, R., (1927) Journal de Madame Rose de Saulces de Freycinet : campagne de l'Uranie (1817-1820). D'après le manuscrit original accompagné de notes par Charles Duplomb [En línea]. París, Société d'éditions géographiques, maritimes et coloniales. Disponible en: http://gallica.bnf.fr/ark:/12148/bpt6k56981727.texteImage [Último acceso el 17 de enero de 2018].

Frézier, A., (1716) Relation du voyage de la mer du Sud aux côtes du Chily et du Perou fait pendant les années 1712, 1713, \& 1714 [En línea]. París, Nyon, Didot, Quillaut. Disponible en: http://bvpb.mcu.es/es/consulta/registro.cmd?id=399545 [Último acceso el 17 de enero de 2018].

G. de Uriarte, C., (2006) "La représentation de la population des îles Canaries dans les récits de voyage" in Études Littéraires. "Les Européens des Lumières face aux Indigènes. Image et textualité", vol. 37, n³, pp. 37-56. 
Gaudichaud, C., (1826) Voyage autour du Monde, entrepris par Ordre du Roi [...] exécuté sur les corvettes de S. M. L'Uranie et La Physicienne, pendant les années 1817, 1818, 1819 et 1820 [En línea]. París, Imprimerie-Librairie de Pillet-Aîné. Disponible en: http:// gallica.bnf.fr/ark:/12148/bpt6k96690q.r=Voyage+autour + du + monde+entrepris + par $+1 \%$ 27+ordre+du+roi.lan [Último acceso el 17 de enero de 2018].

Le Huenen, R., (1990) “Qu'est-ce qu'un récit de voyage?" in Littérales. "Les modèles du récit de voyage", $\mathrm{n}^{\circ} 7$, pp. 11-27.

Léry, J., (1578) Histoire d'un voyage fait en la terre du Brésil autrement dite Amérique [En línea]. Ginebra, Chuppin. Disponible en: http://gallica.bnf.fr/ark:/12148/bpt6k54640v [Último acceso el 17 de enero de 2018].

Lesson, P.A., (1838) Voyage autour du monde entrepris par ordre du gouvernement sur la corvette La Coquille [En línea]. París, Pourrat Frères. Disponible en: http://gallica.bnf.fr/ ark:/12148/bpt6k850917m [Último acceso el 27 de enero de 2018].

Magasich-Airola, J. \& J.M. de Beer, (1994) America Magica. Quand l'Europe de la Renaissance croyait conquérir le Paradis. París, Autrement, col. Mémoires, nº 29.

Milet-Mureau, L.A., (1797) Atlas du voyage de La Pérouse [En línea]. París, Imprimerie de la République. Disponible en: http://gallica.bnf.fr/ark:/12148/btv1b6700354z. [Último acceso el 27 de enero de 2018].

Morlin, I., (2006) “Images pittoresques, texte 'romanesque': la représentation de l'indigène dans le Voyage du chevalier d'Arvieux (Paris, André Cailleau, 1717)" in Études littéraires. "Les Européens des Lumières face aux indigènes. Image et textualité", vol. 37, $\mathrm{n}^{\mathrm{o}} 3$, pp. 15-36.

Moureau, F., (2005) Le théâtre des voyages. Une scénographie de l'Âge classique. "Le récit de voyage : du texte au livre illustré". París, PUPS, pp. 27-43.

Orbigny, A. d', (1835-1847) Voyage dans l'Amérique méridionale... exécuté pendant les années 1826, 1827, 1828, 1829, 1830, 1831, 1832 et 1833 [En línea]. París, Bertrand. 7 vols. Disponible en: http://gallica.bnf.fr/ark:/12148/bpt6k978670.image [Último acceso el 27 de enero de 2018].

Polo, M., (2008) Libro de las maravillas del mundo. Edición de Manuel Carrera Díaz. Madrid, Cátedra. Col. Letras Universales.

Requemora-Gros, S., (2012) Voguer vers la modernité. Le voyage à travers les genres au XVII siècle. París, PUPS.

Requemora-Gros, S. \& L.P. Guyon (dirs.), (2012) Image et voyage. De la Méditerranée aux Indes. Aix-en-Provence, Presses Universitaires de Provence. Coll. Textuelles. Écritures du voyage.

Schlup, M. \& M. Schmidt, (2001) Explorateurs, voyageurs et savants. A la découverte de l'intérieur des continents (Afrique et Amérique du sud). Neuchâtel, Bibliothèque publique et universitaire.

Sonnerat, P., (1776) Voyage à la Nouvelle Guinée [En línea]. París, Ruault. Disponible en: http://gallica.bnf.fr/ark:/12148/bpt6k976036.image [Último acceso el 27 de enero de 2018].

Taillemite, É., (1999) Marins français à la découverte du monde, de Jacques Cartier à Dumont d'Urville. París, Fayard.

Thevet, A., (1558) Les singularitez de la France Antartique, autrement nommée Amérique... [En línea]. París, Héritiers de Maurice de la Porte. Disponible en: http://gallica.bnf.fr/ ark:/12148/bpt6k1041773w [Último acceso el 27 de enero de 2018].

Thevet, A., (1575) La Cosmographie Universelle, illustrée de diverses figures des choses plus remarquables vues par l'auteur [En línea]. París. 2 vols. Disponible en: http:// 
gallica.bnf.fr/ark:/12148/btv1b8626691v.image [Último acceso el 27 de enero de 2018].

Weitzmann, K., (1990) El rollo y el códice. Un estudio del origen y el método de la iluminación de textos. Traducción de Cruz Montero Garrido. Madrid, Nerea. 